\title{
Measuring bedload grain-size distributions with passive acoustic measurements
}

\author{
Thomas Geay ${ }^{1, *}$, Sébastien Zanker ${ }^{2}$, Teodor Petrut $^{1}$ and Alain Recking ${ }^{3}$ \\ ${ }^{1}$ Univ. Grenoble Alpes, CNRS, Grenoble INP, GIPSA-lab, 38000 Grenoble, France \\ ${ }^{2} \mathrm{EDF}$, Division Technique Générale, 38000, Grenoble, France \\ ${ }^{3}$ IRSTEA, UR ETGR, Univ. Grenoble Alpes, 38000 Grenoble, France
}

\begin{abstract}
Bedload Self-Generated Noise (SGN) measurements consist in deploying an underwater microphone (i.e. a hydrophone) in the water course and to record the ambient noise of a river. The use of hydrophones is of interest as it can be easily deployed and can provide a continuous monitoring of bedload transport. However, developments are still required to fully understand how bedload characteristics (e.g. specific flux or granulometry) are related to bedload SGN parameters (e.g. acoustic power and spectrum). Laboratory experiments have shown that central and peak frequencies of bedload noise decrease as the particle size increases, just like in string instruments where the tone frequency decreases from a narrow string to a broader string. In this paper, we propose to test a new inverse method enabling the estimation of bedload grain size distributions from SGN measurements. The inverse method is based on a theoretical modelling of the noise generated by a bedload mixture. SGN and physical sampling measurements have been made in 5 French alpine rivers having several transport conditions (bedload $D_{50}$ from 1 to $40 \mathrm{~mm}$ ) and varying slopes $(0.05$ to $1 \%)$. Measurements were made for specific bedload flux varying from 10 to $150 \mathrm{~g} \cdot \mathrm{m}^{-1} \mathrm{~s}^{-1}$. The proposed inverse method was used to estimate the bedload grain size distributions. SGN results are compared to bedload samples and are found to largely overestimate sampled granulometries. Finally, it is observed that the spectral characteristics of bedload SGN are not related to bedload GSD but rather to the roughness of the river bed, acting as a source of attenuation and shaping bedload SGN spectra.
\end{abstract}

\footnotetext{
* Corresponding author: th.geay@gmail.com
} 


\section{Introduction}

Surrogate methods are beneficial for studying bedload processes when direct samplings are not practicable or when continuous-automatic observations are requested. Passive acoustic monitoring is one of the methods currently developed to monitor bedload fluxes and grain size distributions. The method consists in recording, with hydrophones, the acoustic noise generated by sediment impacts on the river bed. This paper investigates the relationship between bedload Grain Size Distributions (GSD) and spectral information of bedload SelfGenerated Noise (SGN). Field experiments, including bedload samplings with pressuredifference samplers and SGN measurements with hydrophones, are presented.

The use of passive acoustics has been initiated in the middle of the $20^{\text {th }}$ century $[1,2]$ by attempting to relate the acoustic power of bedload SGN (in $\mu \mathrm{Pa}^{2}$ ) to the transported mass of bedload sediments. In the $1980 \mathrm{~s}$, laboratory measurements [3, 4] and theoretical studies [5] showed that spectral information is related to bedload grain-sizes. Two spectral parameters were used: (1) the peak frequency $\boldsymbol{f}_{\boldsymbol{p} \text { eak }}$ and (2) the central frequency $\boldsymbol{f}_{\boldsymbol{c}}$, both expressed in Hz. The frequency $\boldsymbol{f}_{\text {peak }}$ corresponds to the maximum of Power Spectral Density (PSD in $\mu \mathrm{Pa}^{2} / \mathrm{Hz}$ ). The frequency $\boldsymbol{f}_{c}$ represents the centroid frequency of the $\boldsymbol{P S D}$, computed as:

$$
\int_{f \min }^{f_{c}} P S D(f) d f=\int_{f_{c}}^{f \max } P S D(f) d f
$$

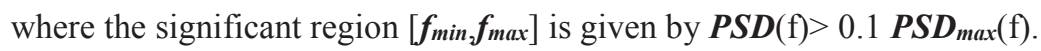

For uniform grain-size mixtures, it has been found that these characteristic frequencies were almost inversely proportional to $\boldsymbol{D}$, the grain diameter $(\mathrm{m})$ :

$$
\begin{gathered}
f_{\text {peak }}=\frac{224}{D^{0.9}} \\
f_{c}=\frac{209}{D^{0.88}}
\end{gathered}
$$

Equations (2) and (3) were used in several studies to estimate bedload diameter from passive acoustic measurements $[6,7,8]$. None of these studies discussed the accuracy of these laws in field experiments, and yet, these equations give a unique-equivalent bedload diameter whereas bedload diameters are defined by grain-size distributions. In the Drau river, it has been found that the $D_{50}$ and $D_{90}$ sizes measured by a sampler correspond to the central frequency and the peak frequency, respectively [9]. More recently, Petrut et al. [10] proposed an inverse method enabling the determination of Grain-Size Distribution from bedload SGN spectrum. This method is based on a theoretical modelling of a sediment mixture impinging a fixed-massive river bed. The acoustic signal generated by the transported mixture is equal to the sum of individual shocks. Every single shock is modelled according to the diameter of the transported particle and its impact velocity. The algorithm founds the most probable relative quantity of shocks (for each granulometric class) that is required to best reproduced the measured spectrum. This procedure showed good agreement with bedload sampling measurements in a large gravel bed river.

In this paper, we propose to test the laws proposed by P.D. Thorne (eq. 2 and 3) and the algorithm described in Petrut et al. [10]. SGN and sampling measurements have been done in five alpine rivers with slopes varying from 0.05 to $1 \%$. Estimated GSDs with acoustics are compared to GSDs that have been sampled with pressure difference samplers. 


\section{Methodology}

\subsection{Field sites}

A description of the field sites is presented in the Table 1. Slopes have been locally measured over reaches starting $100 \mathrm{~m}$ upstream and ending $100 \mathrm{~m}$ downstream the measurements. Granulometric data have been obtained with Wolmann samplings on the closest emerged bars. Discharge and surface velocity have been monitored (or estimated) with data from SVR Radar Guns or acoustic Doppler current profilers. Averaged data are for the entire cross-section. Suspended sediment concentrations were also monitored with turbidity meter and was below $0.5 \mathrm{~g} / 1$ for all sites.

Table 1. Geometric and hydraulic parameters of the field sites.

\begin{tabular}{|c|c|c|c|c|c|c|c|}
\hline River & $\begin{array}{l}\text { Slope } \\
\text { (\%) }\end{array}$ & $\begin{array}{l}\text { Width } \\
\text { (m) }\end{array}$ & $\begin{array}{l}\text { Surfacic } \\
\text { granulo- } \\
\text { metry } \\
{\left[\mathrm{D}_{50}-\mathrm{D}_{84}\right]} \\
(\mathrm{mm})\end{array}$ & $\begin{array}{l}\text { Date of fields } \\
\text { experiments }\end{array}$ & $\begin{array}{l}\text { Discharge } \\
\left(\mathrm{m}^{3} / \mathrm{s}\right)\end{array}$ & $\begin{array}{l}\text { Averaged } \\
\text { water depth } \\
\text { (m) }\end{array}$ & $\begin{array}{l}\text { Averaged } \\
\text { surface } \\
\text { velocity } \\
(\mathrm{m} / \mathrm{s})\end{array}$ \\
\hline Arve & 0.75 & 14 & [70-120] & $\begin{array}{l}2017-06-27 \\
2017-06-28\end{array}$ & $\begin{array}{l}38 \\
29\end{array}$ & $\begin{array}{l}1.25 \\
1.1\end{array}$ & $\begin{array}{l}2.3 \\
1.95\end{array}$ \\
\hline $\begin{array}{l}\text { Grand } \\
\text { Buëch }\end{array}$ & 0.70 & 13 & [30-66] & 2017-05-15 & 13 & 0.6 & 1.85 \\
\hline Isère & 0.05 & 60 & [14-22] & 2017-06-06 & 237 & 2.8 & 1.85 \\
\hline Romanche & 0.13 & 38 & [20-39] & 2017-06-14 & 55 & 1.2 & 1.85 \\
\hline Séveraisse & 1.00 & 13 & [32-75] & $\begin{array}{l}2017-05-17 \\
2017-05-30\end{array}$ & $\begin{array}{l}14 \\
16\end{array}$ & $\begin{array}{l}0.6 \\
0.7\end{array}$ & $\begin{array}{l}2.4 \\
2.5\end{array}$ \\
\hline
\end{tabular}

\subsection{Bedload samplings}

Two types of bedload samplers were used for this study (Fig. 1). For the largest rivers (Romanche and Isère), a Toutle River 2 sampler (305 by $152 \mathrm{~mm}$ ) with a mesh size of $0.75 \mathrm{~mm}$ was deployed from a bridge with a crane. For smaller rivers, an Elwha sampler (229 by $152 \mathrm{~mm}$ ) with a mesh size of $0.5 \mathrm{~mm}$ was handheld with a long pole. The duration of each sample varied between 30 seconds and 8 minutes. Sampling duration were adapted in each stream to ensure that the meshed bag capacity was larger than the sampled volume. Six to twelve locations were sampled across each stream. Each cross-sectional measurement was repeated for at least three times. Bedload samples were dried, sieved and weighted and, bedload specific fluxes were computed for each grain-size class with the following expression:

$$
q_{s, i}=\frac{M_{i}}{d \times W_{\text {sampler }}}
$$

With $q_{s, i}$ the specific bedload flux $\left({\mathrm{g} \cdot \mathrm{m}^{-1} \mathrm{~s}}^{-1}\right)$ of the $i^{\text {th }}$ grain-size class, $M_{i}$ the sampled mass of the $i^{\text {th }}$ grain-size class $(\mathrm{g}), d$ the sampling duration (s) and $W_{\text {sampler }}$ the width of the sampler (m). 
(a)

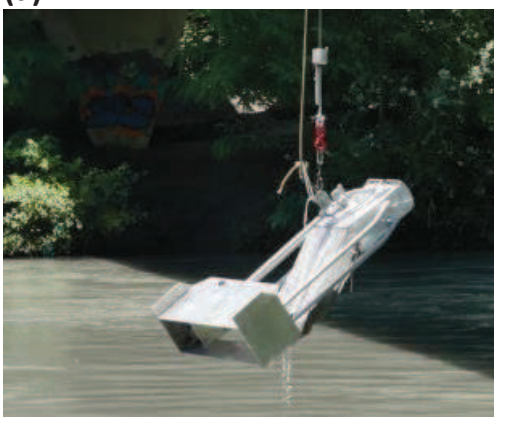

(b)

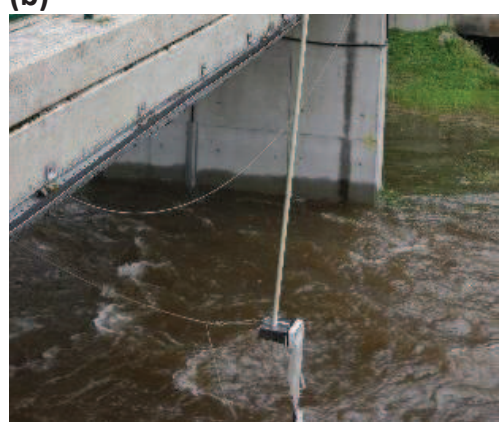

Fig. 1. (a) Toutle River sampler deployed in the Isère River ; (b) Elwha sampler deployed in the Selves River.

For each cross-sectional location, the specific flux $q_{s, i}$ is averaged with respect to the number of repetitions. Finally, a total bedload flux is computed by integration over the width of the river. These total bedload fluxes (for each grain-size class) are used to compute cumulative Grain-Size Distribution of bedload transport. Results are shown in the Fig. 2.
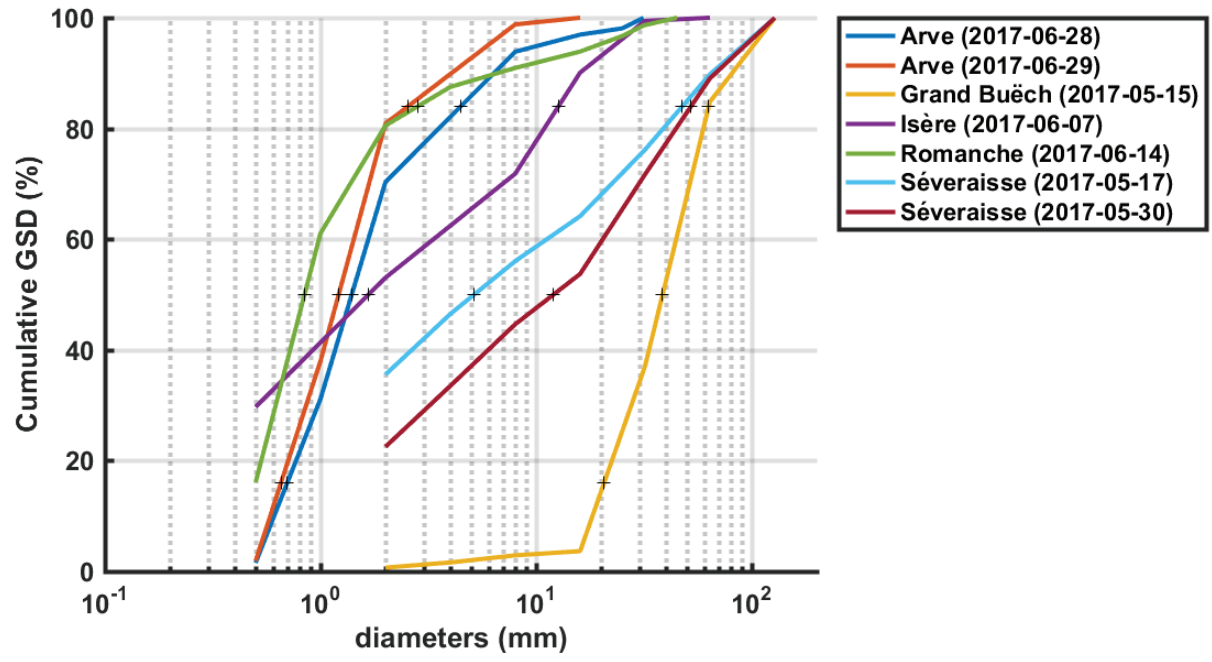

Fig. 2. Cumulative Grain-Size Distribution of sampled bedload fluxes.

\subsection{Self-Generated Noise measurements}

Bedload Self-Generated Noise (SGN) were monitored with HTI-96 hydrophone connected to a EA-SDA14 recorder (RTSys company). Raw acoustic signals were stored in .wav files at a sampling frequency of 156 or $312 \mathrm{kHz}$. The system was mounted on Carlson river board, drifting during the measurements (Fig. 3). The hydrophone was fixed under the river board at a depth, varying between 0.3 and $0.8 \mathrm{~m}$ from the water surface according to the mean water depth. Lagrangian (Drift) measurements were choosen instead of fix-position measurements to maximize the signal to noise ratio of bedload signal. Six to twelve drifts were done along each cross-section, at equally spaced positions. Each cross-sectional position was repeated at least 3 times. Drift duration varied from 10 to 60 seconds according to field hydraulic constraints. The median Power Spectral Density (PSD) of each 
drift has been computed using local windows of approximately 20 milliseconds and overlapping rate of $50 \%$.

(a)

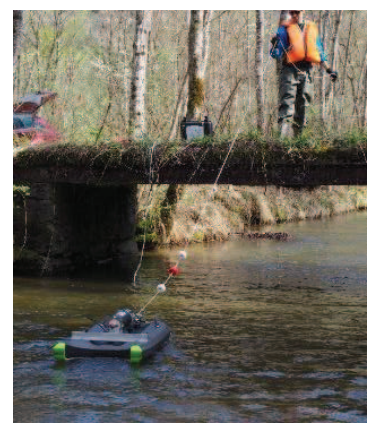

(b)

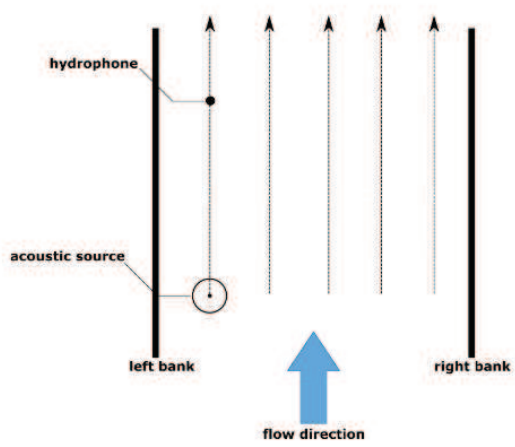

Fig. 3. (a) Drifting board on which the hydrophone and the acoustic recorder were mounted; (b) Drift trajectories of the board during the measurements.
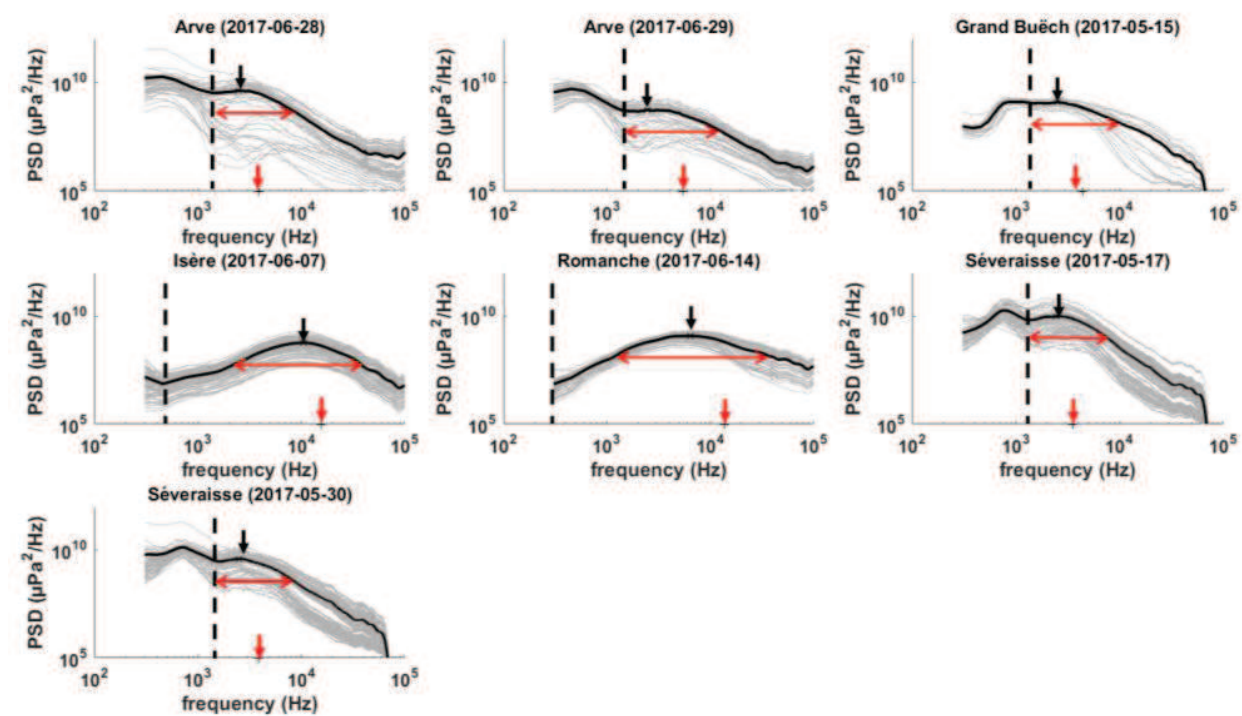

Fig. 4. Power Spectral Densities (PSD in $\mu \mathrm{Pa}^{2} / \mathrm{Hz}$ ) monitored for each stream: logarithmic scales. The black thick line PSD corresponds to the averaged response of the hydrophone along the cross-section. Dashed lines indicate the lowest frequency for which bedload transport is considered to dominate the acoustic signal. Black and red vertical arrows indicate the peak and, respectively, the central frequencies of bedload PSD. Horizontal arrows in red correspond to the bandwidth whose power is at least $10 \%$ of PSD maximum.

Monitored PSDs are plotted in the Fig. 4. Ambient sounds vary in each field site. In all sites, bedload SGN can be clearly heard. Hereby, the bedload dominates the signal in the higher range of frequency. The water agitation noise can also be heard in the Arve, GrandBuëch and Séveraisse rivers. With a visual estimation on the short-term spectrograms, it has been found that the contribution of water flowing noise was located around $1 \mathrm{kHz}$, as 
stated in other studies $[11,12]$. Water agitation noise creates a bi-modal distribution of the power along frequency and masks bedload SGN at lower frequencies. In the Arve, GrandBuëch and Séveraisse rivers, the power contained below $1 \mathrm{kHz}$ represents 10 to $35 \%$ of the total power: acoustic parameters, such as the central frequency, are affected by this water flowing noise and may not be representative of bedload SGN spectrum. To avoid the contribution of flowing water in the measured PSDs, PSDs have been truncated at the frequency corresponding to the local minimum existing around $1000 \mathrm{~Hz}$ (Fig. 4 and 6, dashed lines). Central and peak frequencies are then computed in the part of the PSD dominated by bedload SGN (i.e. in the higher frequency range).
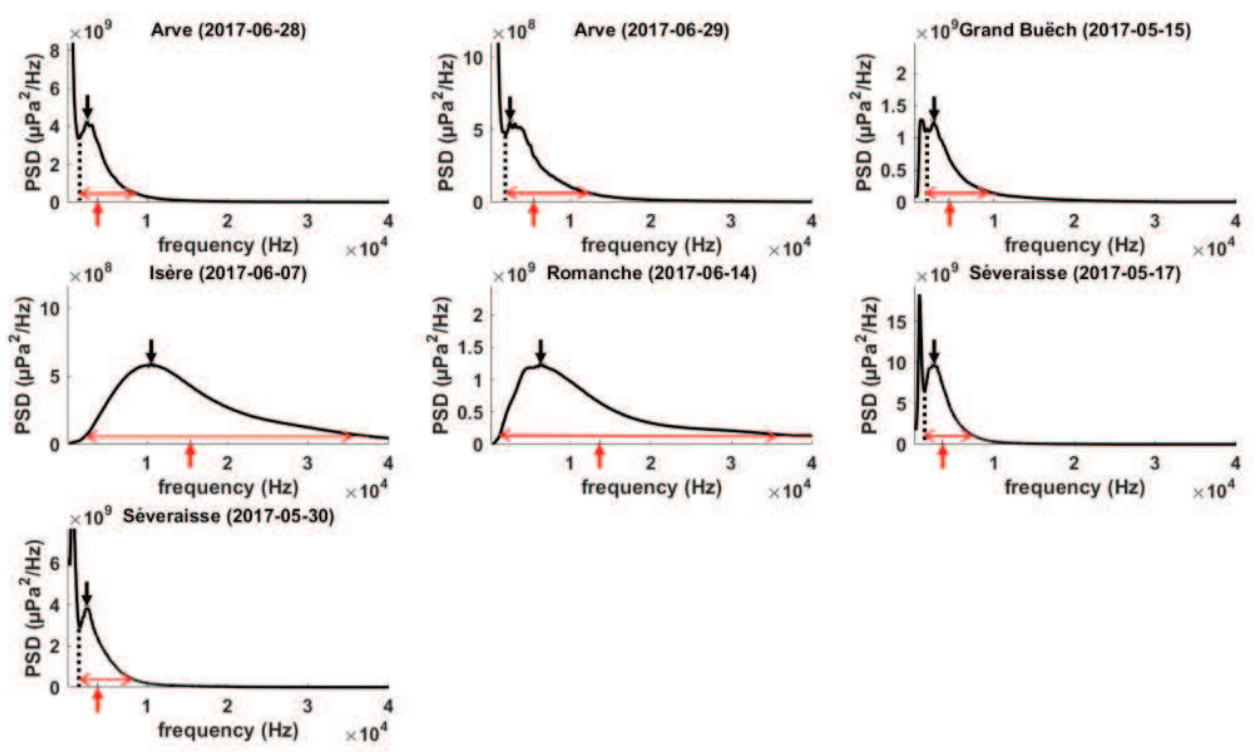

Fig. 5. Linear representations of the averaged Power Spectral Densities of SGN measurements. Symbols are defined in the caption of Fig. 4.

\section{Results}

Based on average PSD and on Thorne's law (eq. 2 and 3), equivalent diameters have been estimated and are compared with sampled diameters (Fig. 6). It was found that equivalent diameters are much larger than the sampled diameters. Similar results are obtained using the algorithm of Petrut et al. [10]. Estimated grain-size distributions are much larger than the sampled GSDs, no matter the values of parameters used in the inversion model (e.g. impact velocities). Both methods failed to approximate the grain size distributions that have been measured with the pressure difference samplers. 


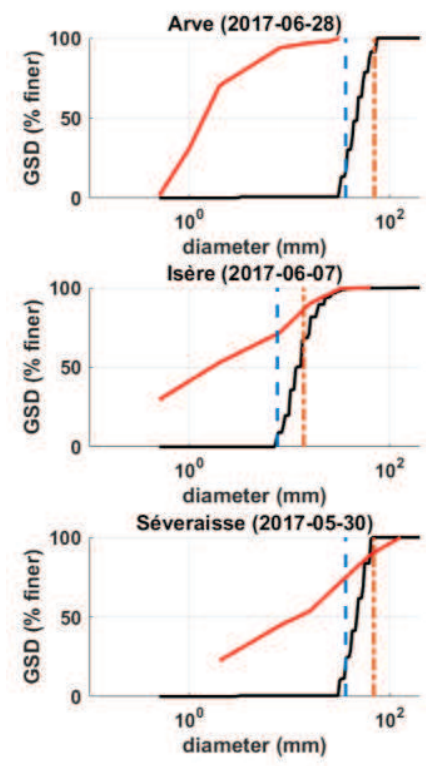

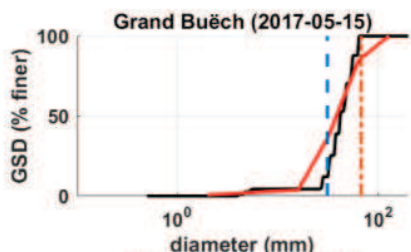

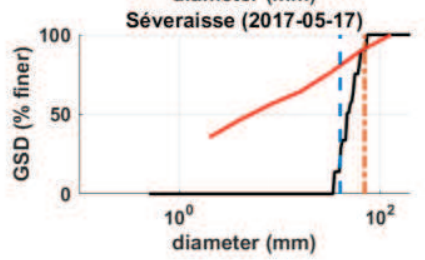

Fig. 6. Black curves: estimated cumulative GSD using the algorithm of Petrut et al. [10]. Red curves: sampled GSD. An impact velocity of $0.1 \mathrm{~m} / \mathrm{s}$ has been assumed for modeling the bedload impacts.

\section{Discussion}

Regardless the method used to inverse SGN spectrum, empirical Thorne's laws or Petrut et al.'s procedure, it has been found that estimated diameters are much larger than sampled diameters. It means that the acoustic signals have not enough power in the higher frequency bands that describe the bedload transport of fine materials. Concerning the ability of fine sediments to generate SGN, we should mention that Thorne's experiments (and calibration laws) were made with materials having diameters even finer than $1 \mathrm{~mm}$. However, it is still possible that sand particles do not generate sounds in our field sites because they are rather transported in quasi-suspension, without impacting the river bed.

Our results can also be interpreted in the light of the attenuation processes occurring when acoustic waves propagate in the water column. Laboratory experiments showed the river-bed roughness affects the attenuation coefficient [13]: larger roughness involve larger attenuation for gravel to cobbles river-bed due to scattering by diffraction processes. In a field experiment, Rigby et al. [14] observed that the attenuation is frequency dependent: attenuation was larger for higher frequencies, i.e. 5, 10 and $20 \mathrm{kHz}$. In the case of our field sites, the roughness of the river-bed can be approximated by the largest diameters sampled on the gravel bars nearby the measurements (Table 1). We found that the spectral parameters of bedload SGN ( $\boldsymbol{f}_{\boldsymbol{c}}$ and $\boldsymbol{f}_{\text {peak }}$ ) are correlated with the sampled D84 of the bars (Fig. 7). The larger the diameters of the river bed is, the lower the frequency characterizing the power spectral densities of bedload SGN is. Larger roughness involves larger attenuation and as this effect is frequency dependent, monitored PSDs are less powerful in the higher frequency range with an increasing river-bed roughness. 


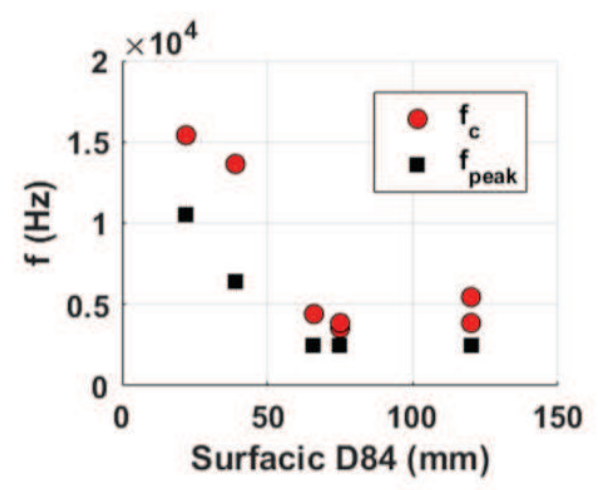

Fig. 7. $\mathbf{f}_{\mathbf{c}}$ and $\mathbf{f}_{\text {peak }}(\mathbf{H z})$ variations in function of surfacic $\mathbf{D}_{\mathbf{8 4}}$ of emerged bars $(\mathrm{mm})$.

\section{Conclusion}

Bedload sampling and SGN measurements have been performed in five gravel-bed rivers. Based on the power spectral densities of acoustic signals, grains size distributions and equivalent diameters have been estimated by using Thorne's laws and the algorithm of Petrut et al. [10]. Regardless the method used, estimated diameters failed to approximate the sampled grain size distributions. It has been observed that characteristic frequencies of bedload SGN were not related to sampled diameters but rather to the largest diameters sampled from the nearby gravel bars. As it has been observed that river-bed roughness is a source of attenuation of acoustic wave, so we conclude that the frequency content of bedload SGN is more representative for the propagation effects than for the bedload grain size distribution. Before any estimation of bedload parameters with passive acoustic, a better understanding of acoustic propagation laws in rivers is required to deconvolute the monitored signals from propagation effects. 


\section{References}

1. K. Bedeus, L. Ivicsics, Observation of the noise of bed load. General Assembly, Commission on Hydrometry, International Association of Hydrological Sciences, Berkeley, CA, USA: 19-31 (1963)

2. C.K. Jonys, Acoustic measurement of sediment transport. Scientific Series: 64 (1976)

3. P.D. Thorne, The measurement of acoustic noise generated by moving artificial sediments, J. Acoust. Soc. Am. 78: 1013-1023 (1985)

4. P.D. Thorne, Laboratory and marine measurements on the acoustic detection of sediment transport, J. Acoust. Soc. Am. 80: 899-910. DOI: 10.1121/1.393913 (1986)

5. P.D. Thorne, D. Foden, Generation of underwater sound by colliding spheres, $J$. Acoust. Soc. Am. 84: 2144-2152 (1988)

6. T. Mason, D. Priestley, D.E. Reeve, Monitoring near-shore shingle transport under waves using a passive acoustic technique. J. Acoust. Soc. Am. 122: 737-746 (2007)

7. C. Bassett, J. Thomson, B. Polagye, Sediment-generated noise and bed stress in a tidal channel. J. Geophys. Res-Oceans 118: 2249-2265 (2013)

8. M.D. Marineau, S.A. Wright, D. Gaeuman, Calibration of sediment-generated noise measured using hydrophones to bedload transport in the Trinity River, California, USA. Proc. of River Flow conference : 1519-1526 (2016)

9. T. Geay, P. Belleudy, C. Gervaise, H. Habersack, J. Aigner, A. Kreisler, H. Seitz, J.B. Laronne, Passive acoustic monitoring of bed load discharge in a large gravel bed river. J. Geophy. Res-Earth 122: 528-545 (2017)

10. T. Petrut, T. Geay, C. Gervaise, P. Belleudy, S. Zanker, Passive Acoustic Measurement of Bedload Grain Size Distribution using the Self-Generated Noise. Hydrol. Earth Syst. Sc.22: 767-787 (2018)

11. D. Tonolla, M.S. Lorang, K. Heutschi, K. Tockner, A flume experiment to examine underwater sound generation by flowing water. Aquat. Sci. 71: 449-462. (2009)

12. D. Tonolla; V. Acuña, M.S. Lorang, K. Heutschi, K. Tockner, A field-based investigation to examine underwater soundscapes of five common river habitats. Hydrol. Process. 24: 3146-3156 (2010)

13. D.G. Wren, B.T. Goodwiller, J.R. Rigby, W.O. Carpenter, R.A. Kuhnle, J.P. Chambers, Sediment-Generated Noise (SGN): laboratory determination of measurement volume, Proc. of the 3rd Joint Federal Interagency Conference (10th Federal Interagency Sedimentation Conference and 5th Federal Interagency Hydrologic Modeling Conference), April 19 - 23, 2015, Reno, Nevada. D: 408-413 (2015)

14. J.R. Rigby, D. Wren, N. Murray, Acoustic signal propagation and measurement in natural stream channels for application to surrogate bed load measurements: Halfmoon Creek, Colorado. Proc. of River Flow conference : 1566-1570 (2016) 